\title{
Seasonal behaviour of upper ocean freshwater content in the Bay of Bengal: synergistic approach using model and satellite data
}

\author{
Smitha Ratheesh ${ }^{1, *}$, Neeraj Agarwal ${ }^{1}$, Rashmi Sharma ${ }^{1}$, K. V. S. R. Prasad ${ }^{2}$ and \\ Sujit Basu ${ }^{3}$
}

${ }^{1}$ Space Applications Centre, Oceanic Sciences Division, Ahmedabad 380 058, India
${ }^{2}$ Department of Meteorology and Oceanography, Andhra University, Visakhapatnam 530 003, India
${ }^{3}$ Space Applications Centre, Ahmedabad 380 058, India

Any change in precipitation, evaporation and river discharge, by virtue of its impact on the distribution of ocean salinity, leaves its inevitable signature on the freshwater content (FWC) in the oceans. In this study, synergistic use of satellite data and numerical ocean circulation model is explored to examine the seasonality of FWC of the upper $30 \mathrm{~m}$ water column of the Bay of Bengal (BoB). For this purpose, first the sea surface salinity (SSS) from Aquarius is assimilated into a model of the Indian Ocean. Strength of assimilation is judged by comparing simulated SSS with satellite and Argo datasets. An overall improvement of $39 \%$ is observed in SSS over free run of the model without data assimilation. Next, the focus is shifted to the spatial and temporal variability of FWC of the upper $30 \mathrm{~m}$ of $\mathrm{BoB}$ in relation to the different components of freshwater forcing. A delay of three months in the peak of FWC is observed with respect to the peak of net freshwater influx for $B o B$ as a whole. However, the nature of the response of FWC to the total freshwater input forcing in the major river-dominated regions of $\mathrm{BoB}$ is different from that for the whole $B o B$. The relative role of river influx in controlling FWC in these regions is well brought out in the study. For the Ganga-Brahmaputra region, river run-off is observed to be a crucial parameter in regulating FWC, whereas for both Irrawaddy river region and central $B o B$, precipitation dominates the response. The response of salinity in the uppermost part of the northern BoB to the total freshwater input is much more rapid than in the other regions.

Keywords: Freshwater content, sea surface salinity, seasonal variability, upper ocean region.

THE Bay of Bengal (BoB) is an important basin of the global ocean where freshwater plays a crucial role in controlling its thermodynamic and dynamic behaviour. This part of the Indian Ocean (IO) is a sink of many large and small rivers which discharge nearly $2950 \mathrm{~km}^{3}$ of fresh-

\footnotetext{
*For correspondence. (e-mail: smitha@sac.isro.gov.in)
}

water annually into it ${ }^{1}$. The large amount of river discharge along with evaporation $(E)$ and precipitation $(P)$ plays a key role in the evolution of global climate by affecting the thermohaline structure of the ocean ${ }^{2-4}$. The salinity stratification at the peak of summer monsoon, which owes its origin to the accumulation of freshwater in the upper ocean, shallows the mixed layer in the BoB. As a consequence, the barrier layer thickens in the BoB, especially in regions highly affected by freshwater from the major rivers, namely Ganga, Brahmaputra and Irrawaddy ${ }^{3}$. Also the rivers Krishna, Godavari, Subarnarekha and Mahanadi contribute to the total freshwater flux in the BoB, thereby further reducing salinity, especially north of $12^{\circ} \mathrm{N}$. Trapped solar radiation in the mixed layer can trigger cyclone activities in the $\mathrm{BoB}$ by providing high sea surface temperature (SST) threshold needed for the formation of a cyclone ${ }^{5,6}$. Interestingly, the IO experiences two different thermodynamic conditions in the two basins of its northern extent, namely the Arabian Sea (AS) and the BoB, although both basins share the same latitudinal belt. The upper density stratification differs markedly for these regions with high haline stratification in the BoB, especially in northern bay, due to the presence of large freshwater from precipitation and river run-off $f^{7,8}$.

The variability of the freshwater content (FWC) is important for an understanding of the global hydrological cycle and earth's climate. Any change in precipitation, evaporation and river discharge plays a crucial role in the distribution of salinity, thereby leaving its mark on the FWC. Since the BoB receives an enormous amount of precipitation and river discharge, a study of the seasonal variability of FWC in the $\mathrm{BoB}$ is important in the current context. However, such studies are few compared to those of salinity variability. In fact, it can be mentioned that the study of FWC variability in the IO is still in its infancy. Quite some time ago, a study shed some light on the IO freshwater transport ${ }^{9}$. A recent study has shown that major part of the river water in the $\mathrm{BoB}$ is carried southward through the East India Equatorial Current during the northeast monsoon ${ }^{10}$. However, basin-wise study of the IO was absent in that paper. Also, the BoB 
was not divided into subregions to clearly bring out the role of various rivers as has been done here.

With the advent of operational space-borne microwave radiometers in recent years, synoptic measurement of sea surface salinity (SSS) became possible through satellites such as Soil Moisture Ocean Salinity (SMOS) and Aquarius. Although the spatial resolution of such space-borne observations is insufficient to delineate the sub-mesoscale features, their synoptic coverage is more than sufficient to monitor basin-scale phenomena such as salinity changes during the Indian summer monsoon. However, satellites in isolation are unable to study FWC variability in its totality as they derive only the surface information and the quality of satellite data in the coastal region is questionable. Though Argo floats and other in situ datasets provide subsurface information of salinity, they are sparse in general and more so in the BoB. Proper representation of freshwater fluxes for a realistic estimate of salt and freshwater budget is a major research area in oceanography in general and ocean modelling in particular. It has become quite apparent now that assimilation of SSS provides a more realistic salinity field rather than the use of climatology ${ }^{11,12}$. Hence, in this study we explore the synergistic use of satellite data and model field to study the seasonality of the upper ocean FWC of the BoB by assimilating SSS from satellites into the model.

\section{Model, data and methodology used}

The Princeton Ocean Model (POM) configured for the IO has been used in this study. It is a terrain-following sigma-coordinate, free surface, primitive equation model developed at Princeton University, $\mathrm{USA}^{13}$. The model contains turbulence sub-closure scheme modified to provide better vertical coefficients ${ }^{14}$. Closure 2.5 has been used together with a prognostic equation for the turbulence macroscale. The external and internal time-steps are $30 \mathrm{~s}$ and $1200 \mathrm{~s}$, respectively. The model bottom topography is derived from the $2 \mathrm{~min}$ resolution ETOPO2 database. The model domain extends from $20^{\circ} \mathrm{S}$ to $25^{\circ} \mathrm{N}$ and $40^{\circ} \mathrm{E}$ to $100^{\circ} \mathrm{E}$. The horizontal resolution of the model has been set to $0.5^{\circ} \times 0.5^{\circ}$. The model has 25 sigma levels in the vertical. The advantage of sigma level is that it provides high vertical resolution near the coast. The northern and western boundaries of the model domain are closed. Standard radiation boundary conditions are used at the open southern boundary and at the open part of the eastern boundary ${ }^{15}$. UNESCO monthly climatology of river discharge is used to incorporate major rivers such as the Ganga, Brahmaputra, Irrawaddy, Krishna, Godavari and Subarnarekha in the model. River discharge is distributed over a horizontal area proportional to the rate of discharge. This model has been used in several studies of the $\mathrm{IO}^{16-19}$.

After a spin-up run for 30 years with monthly climatological forcings for the establishment of steady annual cycle, an interannual run is performed for the years 20012015. In this run, the model is forced by daily fields of net shortwave and longwave radiation, precipitation, specific humidity and wind fields from the National Center for Environmental Prediction (NCEP). The weekly model states from the historical run for the years 2005-07 are utilized to create the static ensemble to be used in the data assimilation. Ensemble optimal interpolation (EnOI) technique is used for assimilation. It is a multivariate technique and through innovation vector and Kalman gain matrix, the effect of surface assimilation is spread into subsurface levels as a result of which all the model prognostic parameters get suitably modified. Due to lack of space, the assimilation technique has not been explained in detail here. Interested readers are referred to the earlier studies ${ }^{19-22}$. EnOI is a robust method utilized in earlier studies using the POM model for assimilation of sea-level anomaly (SLA) and $\mathrm{SST}^{19,22}$. Considerable improvement in surface and subsurface parameters of the model has been noticed. For the present study, assimilation run spans the duration August 2011 to April 2015, as dictated by the availability of Aquarius SSS data.

Daily SSS data obtained from Aquarius mission are used for the study. The satellite was launched in August 2011 and the spatial resolution is approximately $100 \mathrm{~km}$ with a $300 \mathrm{~km}$ wide $\mathrm{swath}^{23}$. These data are gridded with a resolution of $1^{\circ} \times 1^{\circ}$ over swath and obtained from ftp://podaac.jpl.nasa.gov/allData/aquarius/. SSS derived from Aquarius over the IO has been studied and validated with Argo $\mathrm{SSS}^{24,25}$. It is found that Aquarius is able to capture the features of SSS distribution.

For validating model salinity, salinity profiles from Argo floats (www.argo.net) are used. Performance of assimilation run in comparison with that of free run is estimated using a skill score analysis, which shows improvement in root mean square error (RMSE) of the assimilation run over the free run (SSS from Argo being used as reference). For this purpose, salinity from both model runs and Argo floats is vertically interpolated to the same depths and then collocated in both spatial and temporal domains. A window of 1 day is chosen for temporal collocation and for spatial collocation model point nearest to Argo location within a $0.5^{\circ}$ distance (model resolution) is selected. A total of 10,201 collocated points are obtained after performing the necessary quality checks mentioned in the Argo user manual for the study period 1 January 2012 to 31 December 2014.

$$
\text { Skill score }=\left(\frac{\mathrm{RMSE}_{\text {free run }}-\mathrm{RMSE}_{\text {assim run }}}{\mathrm{RMSE}_{\text {free run }}}\right) * 100 \text {, }
$$

where $\mathrm{RMSE}_{\text {free run }}$ and $\mathrm{RMSE}_{\text {assim run }}$ are the RMSEs computed for salinity from free run and assimilation run respectively, with salinity from Argo floats serving as reference. 
To understand the relation between FWC and total freshwater input, FWC for different seasons, regionintegrated FWC and total freshwater input are computed over the study region using the following equations ${ }^{9,26,27}$.

FWC is calculated as follows

$$
\mathrm{FWC}=\int_{-H}^{0}\left(1-\frac{S}{S_{\mathrm{ref}}}\right) \mathrm{d} z
$$

where $S$ is the salinity at various depths $(z), S_{\text {ref }}$ the reference salinity ( $35 \mathrm{psu}$ ) and $H$ is the depth of water column. Reference salinity is computed as area-averaged salinity from the surface to $4000 \mathrm{~m}$ depth over the area encompassing $4^{\circ}-24^{\circ} \mathrm{N}$ and $40^{\circ}-100^{\circ} \mathrm{E}$, using Levitus annual climatology. The unit of FWC is metre (m). Use of single value of reference salinity rather than spatially varying reference salinity can introduce spurious negative values for FWC in the case where actual salinity is greater than the reference value. For the present study, $H$ is chosen to be $30 \mathrm{~m}$ for the inclusion of most of the freshwater in the upper ocean ${ }^{1}$.

Region-integrated FWC is calculated as follows

$$
\mathrm{FWC}_{\text {int }}=\int_{0}^{L} \int_{0}^{L} \mathrm{FWC} \mathrm{d} x \mathrm{~d} y .
$$

Region-integrated total freshwater input is calculated as follows

$$
\mathrm{FF}_{\text {int }}=\int_{0}^{L} \int_{0}^{L}(P-E+R) \mathrm{d} x \mathrm{~d} y,
$$

where $x$ and $y$ are the zonal and meridional coordinates respectively. $L$ represents the zonal or meridional extent, as the case may be. $P, E$ and $R$ are the precipitation, evaporation and river runoff respectively. Importance of river discharge on the variability of FWC is analysed by dividing the study region into three sub-regions encompassing Ganga-Brahmaputra river (G-B) system, Irrawaddy river and rest of the area comprising Krishna and Godavari rivers.

\section{Results}

Before conducting the study using the analysed fields from Aquarius SSS assimilated model runs, validation is performed to understand the improvement obtained in model salinity after assimilation. For this, mean and standard deviation of SSS from both model runs (free run and assimilation run) are compared with those from Aquarius mission and shown in Figure 1 as anomaly of mean and standard deviation of each model run from that of Aquarius. This comparison demonstrates the ability of the model, with assimilation switched on, to provide more faithful representation of salinity variability than the model without assimilation. It is observed that negative bias in the free run for the northern $\mathrm{BoB}$ and in some parts of southeast AS along with the positive bias observed in the other parts of the IO are much less pronounced after the assimilation of SSS. However, the large salinity variability in the IO, such as low SSS in the $\mathrm{BoB}$ and high SSS in the AS, as shown by Aquariusderived SSS, is correctly simulated by both model runs. In the northern $\mathrm{BoB}$, distribution of SSS is strongly dependent on the relative contribution from precipitation and river discharge ${ }^{28}$, and this effect of freshwater flux on $\mathrm{SSS}$ is found to be large in the areas of $\mathrm{G}-\mathrm{B}$ river discharge. Surface water is relatively fresh near the northern BoB and becomes saltier in its southward journey. Strong zonal stratification of SSS in the northern BoB is highly visible in Aquarius SSS and also in SSS from the assimilation run. It is to be noted that the under-estimation of SSS variability to the south of $20^{\circ} \mathrm{N}$ in the $\mathrm{BoB}$ and the over-estimation of SSS variability in the equatorial IO (EIO) and in the AS are corrected by assimilation.

After this initial assessment, the robustness of the model analysis is confirmed by comparing the modelresults with independent observations. For this purpose, Argo-derived salinity data are used to validate model simulated salinity from both assimilation and free runs. Since salinity has a crucial role in the variability of mixed layer depth (MLD), especially for the BoB, improvement of MLD is also computed to assess the performance of assimilation. MLD is calculated as the depth where density is equal to the sea surface density plus incremental density equivalent to decrease in SST by $1^{\circ} \mathrm{C}$ (ref. 29). Validation is performed for different regions for a better understanding of the impact of assimilation in the model domain. The regions selected are the IO $\left(5^{\circ} \mathrm{S}-25^{\circ} \mathrm{N} ; 45^{\circ}-\right.$ $\left.100^{\circ} \mathrm{E}\right), \operatorname{BoB}\left(10^{\circ}-23^{\circ} \mathrm{N} ; 80^{\circ}-100^{\circ} \mathrm{E}\right)$, AS $\left(10^{\circ}-23^{\circ} \mathrm{N}\right.$; $\left.45^{\circ}-79^{\circ} \mathrm{E}\right)$, and EIO $\left(5^{\circ} \mathrm{S}-5^{\circ} \mathrm{N} ; 40^{\circ}-100^{\circ} \mathrm{E}\right)$. Since $30 \mathrm{~m}$ is taken as $H$ in the computation of FWC (see eq. (2)), statistics is provided for the upper $30 \mathrm{~m}$. The results are shown in Figure 2 as skill scores (see eq. (1)) and in Table 1 as RMSEs for assimilation and free runs. Salinity at $1 \mathrm{~m}$ shows an improvement of around 55\%, 30\%, 68\% and $39 \%$ for the AS, BoB, EIO and IO respectively. Salinity at $30 \mathrm{~m}$ also shows similar values of improvement after assimilation, except for the BoB region, where the improvement is reduced to $12 \%$. Positive impact of assimilation is visible up to $100 \mathrm{~m}$ for all the regions, except the BoB, where the impact of assimilation is visible up to $50 \mathrm{~m}$ only. This might be the reason for the deterioration of MLD fields in the $\mathrm{BoB}$ after assimilation, whereas a positive impact of SSS assimilation is visible for the AS and EIO regions. This experiment vividly demonstrates the power of assimilation in improving the salinity fields of the model. These analysed model fields from SSS assimilation are further used in the study. 

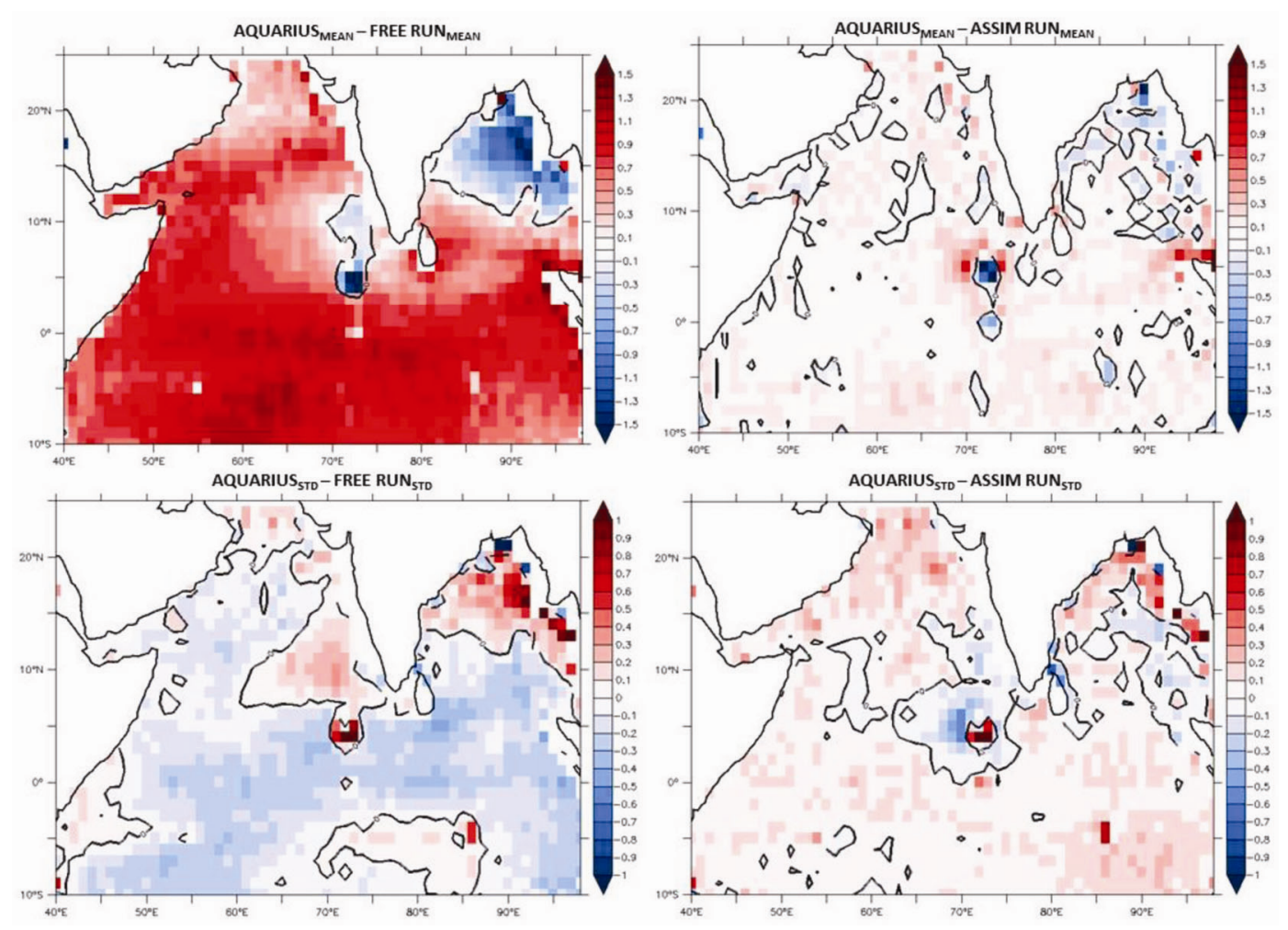

Figure 1. Anomaly of mean (upper row, psu) and standard deviation (bottom row, psu) of sea surface salinity from free run (left column) and assimilation run (right column) with respect to Aquarius sea surface salinity. Blank lines are the zero contours.

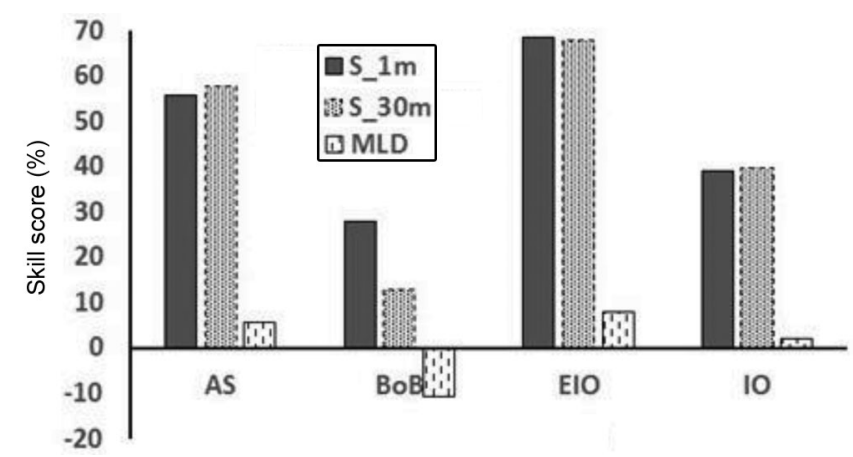

Figure 2. Skill score (\%) of model salinity and MLD computed for different regions: Indian Ocean $\left(5^{\circ} \mathrm{S}-25^{\circ} \mathrm{N} ; 4^{\circ}-100^{\circ} \mathrm{E}\right)$, Bay of Bengal $\left(10^{\circ}-23^{\circ} \mathrm{N} ; 80^{\circ}-100^{\circ} \mathrm{E}\right)$, Arabian Sea $\left(10^{\circ}-23^{\circ} \mathrm{N} ; 45^{\circ}-79^{\circ} \mathrm{E}\right)$, and equatorial Indian Ocean $\left(5^{\circ} \mathrm{S}-5^{\circ} \mathrm{N} ; 40^{\circ}-100^{\circ} \mathrm{E}\right)$. S_ $1 \mathrm{~m}$, Salinity at $1 \mathrm{~m}$ depth; S_30 m, salinity at $30 \mathrm{~m}$ depth; MLD, mixed layer depth.

Figure 3 shows the seasonal behaviour of FWC for the upper $30 \mathrm{~m}$ water column of the IO. A clear distinction in terms of FWC can be made between the eastern and western parts of the north IO. The eastern part is mainly dominated by freshwater and FWC is positive during all the seasons, whereas for the western part FWC is negative during all the seasons especially at some places confined mostly to the northern part. This is mainly due to the fact that the eastern part of the north IO receives significant amount of freshwater through river discharge and precipitation and does not lose much by evaporation ex- cept during winter. In case of the AS, evaporation exceeds the total freshwater input ${ }^{30}$. It is worth mentioning that the area between $10^{\circ}-23^{\circ} \mathrm{N}$ and $80^{\circ}-100^{\circ} \mathrm{E}$ accumulates most of the freshwater in the northern IO (Figure 3). Hence, the focus of the study is on this area and by BoB we henceforth mean this area. Maximum FWC is observed during post-monsoon and minimum during premonsoon over the BoB. It clearly points out that FWC in the ocean mainly depends on the freshwater influx, spatial and temporal distribution of its components such as evaporation $(E)$ and precipitation $(P)$. Understanding the variability of these parameters is necessary for studying the distribution of FWC in the BoB. Figure 4 shows the annual mean of $E, P, P-E$ from NCEP reanalysis and FWC for the BoB. Relatively high evaporation $(5 \mathrm{~mm} /$ day) can be seen in the southeastern part of the $\mathrm{BoB}$, mostly around the longitude of $92^{\circ} \mathrm{E}$ and from the southern $\mathrm{BoB}$ to $16^{\circ} \mathrm{N}$. Precipitation is maximum along the coastal regions of the southeast $\mathrm{BoB}$ and northern BoB. Also high precipitation of $7 \mathrm{~mm} /$ day is observed along the southern $\mathrm{BoB}$ from $81^{\circ} \mathrm{E}$ to $92^{\circ} \mathrm{E}$. The west coast of the BoB shows comparatively less precipitation of $2.5 \mathrm{~mm} /$ day. From Figure $4 c$, it can be observed that $P-E$ is positive over the regions of high precipitation. FWC in Figure $4 d$ follows a zonal pattern of increasing trend towards the northern $\mathrm{BoB}(4 \mathrm{~m})$ and the eastern BoB, mostly along the regions of $\mathrm{G}-\mathrm{B}$ and Irrawaddy river discharge. Though $P-E$ is higher for the southern 
Table 1. RMSE (psu) of subsurface salinity up to $50 \mathrm{~m}$ from model free run and assimilated run

\begin{tabular}{|c|c|c|c|c|c|c|c|c|}
\hline \multirow[b]{2}{*}{ Depth (m) } & \multicolumn{2}{|c|}{ IO } & \multicolumn{2}{|c|}{$\mathrm{BoB}$} & \multicolumn{2}{|c|}{ AS } & \multicolumn{2}{|c|}{ EIO } \\
\hline & RMSE_A & RMSE_F & RMSE_A & RMSE_F & RMSE_A & RMSE_F & RMSE_A & RMSE_F \\
\hline 1 & 0.684 & 1.125 & 0.782 & 1.085 & 0.428 & 0.967 & 0.391 & 1.243 \\
\hline 5 & 0.61 & 1.081 & 0.765 & 1.056 & 0.423 & 0.967 & 0.361 & 1.209 \\
\hline 10 & 0.574 & 1.032 & 0.715 & 0.981 & 0.416 & 0.965 & 0.332 & 1.167 \\
\hline 20 & 0.531 & 0.938 & 0.645 & 0.828 & 0.399 & 0.949 & 0.309 & 1.096 \\
\hline 30 & 0.508 & 0.841 & 0.563 & 0.645 & 0.393 & 0.928 & 0.327 & 1.02 \\
\hline 50 & 0.547 & 0.759 & 0.581 & 0.498 & 0.398 & 0.904 & 0.418 & 0.966 \\
\hline
\end{tabular}

IO, Indian Ocean; BoB, Bay of Bengal; AS, Arabian Sea; EIO, Equatorial Indian Ocean.
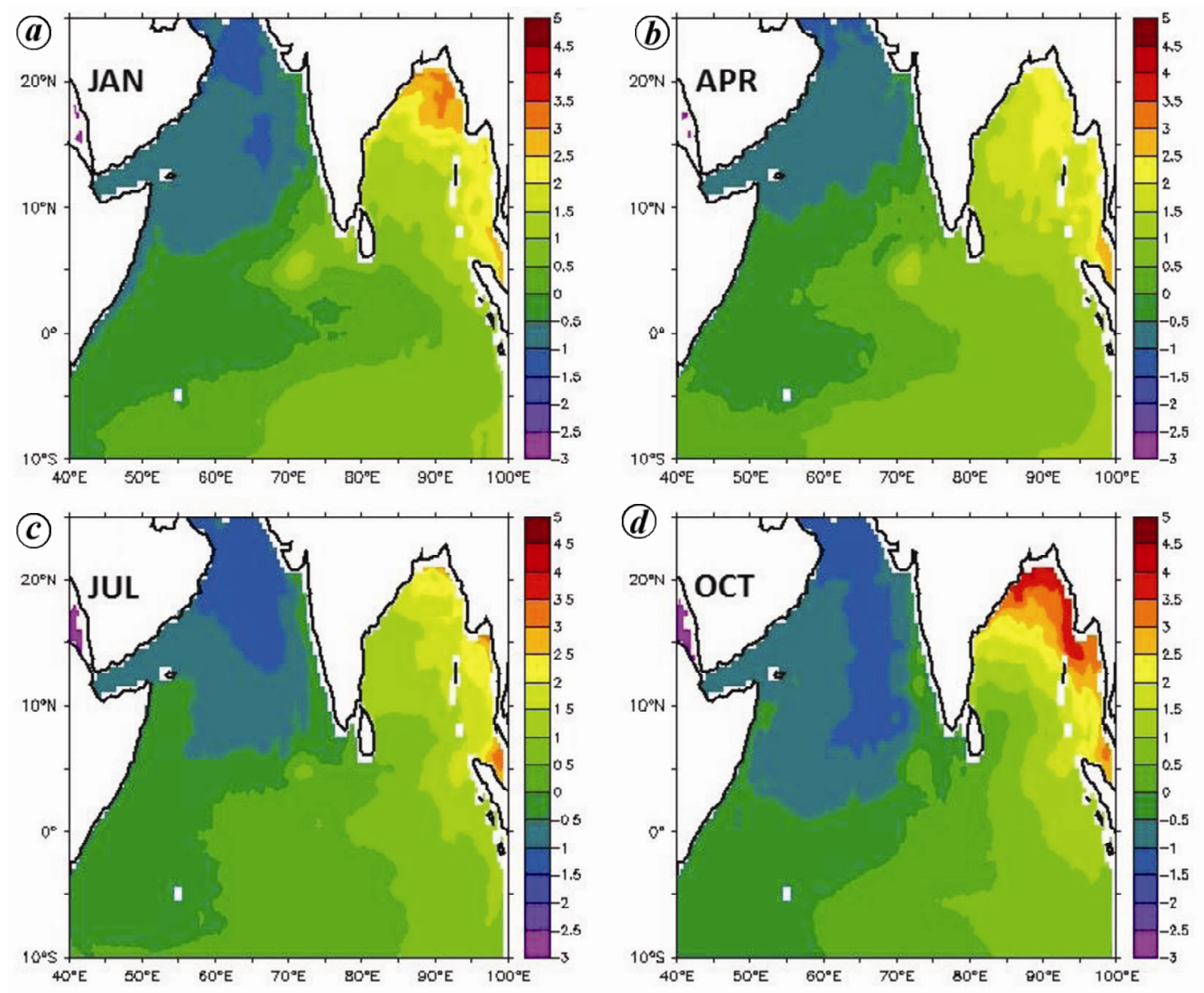

Figure 3. Monthly maps of freshwater content (FWC; m) over the upper $30 \mathrm{~m}$ of the Indian Ocean for (a) January, (b) April, (c) July and (d) October.

BoB from $81^{\circ} \mathrm{E}$ to $92^{\circ} \mathrm{E}$, FWC values are less in that region. This clearly indicates a significant role played by river discharge in controlling $\mathrm{FWC}$ in the $\mathrm{BoB}$.

To understand the response of FWC to the total freshwater input forcing from precipitation, evaporation and river run-off, area-integrated $\mathrm{FWC}$ and total freshwater input are computed over the BoB (Figure 5). Along with FWC over water column of $30 \mathrm{~m}$ (FWC_30 m), FWC over MLD, designated as FWC_mld is also computed for comparison. However, it can be concluded from this study that, FWC_mld merely follows the pattern of MLD and thus FWC_30m, rather than FWC_mld, is a true representative of the pattern of $\mathrm{FWC}$ distribution.

A strong variability of FWC_30m with respect to net freshwater forcing can be observed from the results (Figure 5). FWC in the upper $30 \mathrm{~m}$ water column increases from April $\left(3090 \mathrm{~km}^{3}\right)$ till October $\left(5005 \mathrm{~km}^{3}\right)$, in response to positive freshwater forcing. $\mathrm{FF}_{\text {int }}$ is negative during November to April, mainly due to the large difference in air-sea temperature which promotes evaporation during that period ${ }^{3}$. Low saline waters are observed in accordance with large FWC. A delay of three months is 

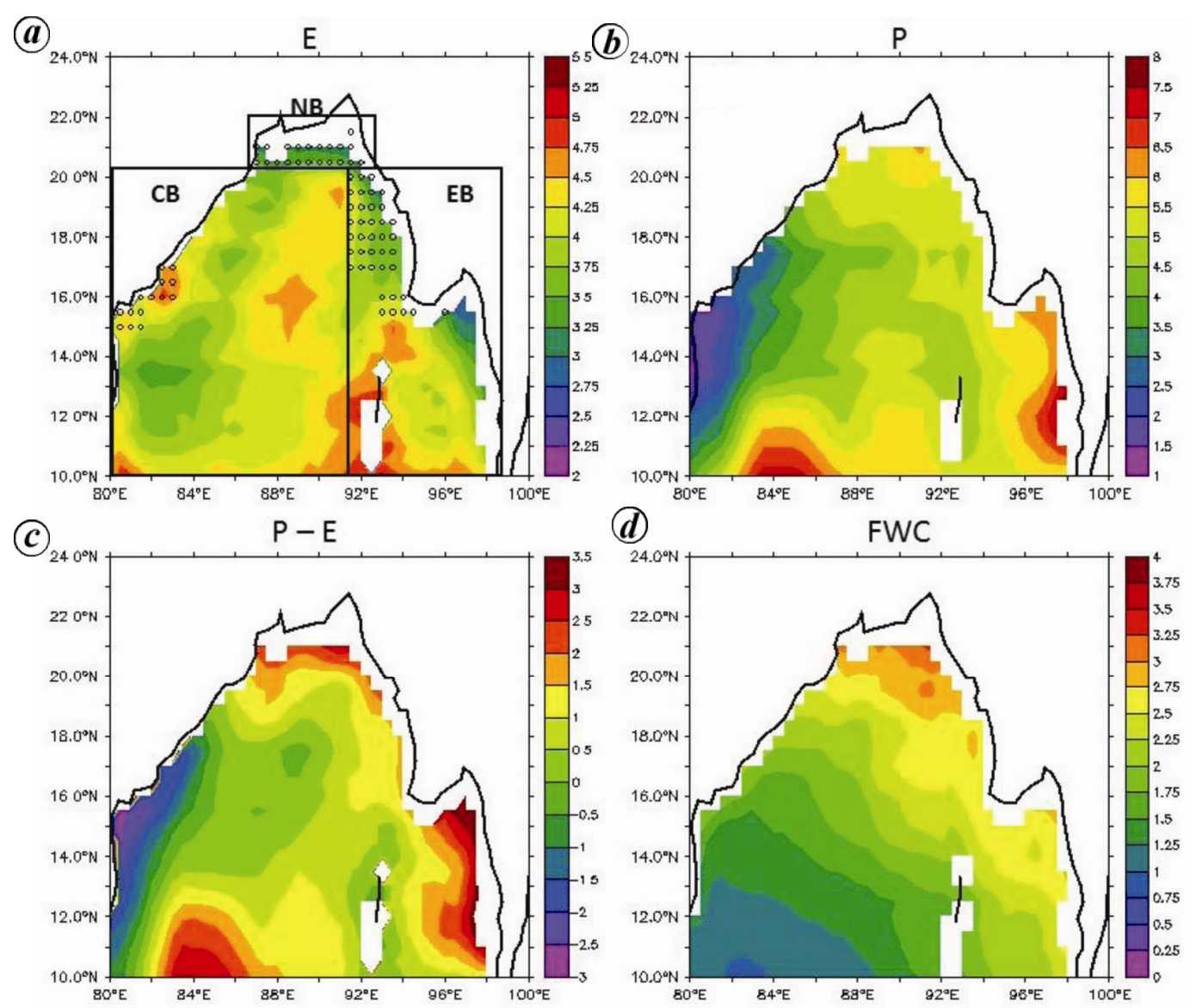

Figure 4. Annual mean of components of freshwater influx ( $\mathrm{mm} /$ day): $(\boldsymbol{a})$ evaporation $(E),(\boldsymbol{b})$ precipitation $(P)$ and $(\boldsymbol{c})$ $P-E$. (d) Annual mean of FWC (m), integrated over the upper $30 \mathrm{~m}$ water column. Open circles in $(\boldsymbol{a})$ show the locations of river discharge distributed over the model domain. Sub-regions mentioned in Figure 6 are also shown as boxes in $(\boldsymbol{a})$.

observed in the peak of FWC_30m with respect to peak $\mathrm{FF}_{\text {int }}$. Salinity (from surface to $30 \mathrm{~m}$ ) in the ocean takes some time to adjust with modified input forcing, lateral and vertical mixing ${ }^{31}$. In fact, it is not salinity, but its instantaneous rate of change which is calculated by the evolution equation. Actual change is an integrated effect where persistence plays a resisting role. Due to the strong relation existing between salinity and $\mathrm{FWC}$, the reason for delay in FWC now becomes fairly obvious. It is worthwhile to mention here that this kind of delay has been reported earlier ${ }^{1}$. Thus it follows that this threemonth delay in the freshening of BoB waters must have its counterpart in a corresponding delay in salinity, and this has been already reported ${ }^{32}$. It is found that salinity minimum during October is delayed by three months from the peak of net freshwater input (August) for the whole BoB. Though many studies have been conducted on the role of freshwater flux in governing the salinity of the $\mathrm{BoB}^{7,33,34}$, there is no study devoted to the understanding of the relation between freshwater input and FWC over the river discharge areas of the BoB, with a realistic representation of salinity using data assimilation. We now divide the study region into three sub-regions to include the $\mathrm{G}-\mathrm{B}$ river system, Irrawaddy river and rest of the BoB. The sub-regions chosen are northernmost BoB (NB, above $20^{\circ} \mathrm{N}, \mathrm{G}-\mathrm{B}$ river discharge area), eastern BoB $\left(\mathrm{EB}, 92^{\circ}-100^{\circ} \mathrm{E} ; 10^{\circ}-20^{\circ} \mathrm{N}\right.$, Irrawaddy river discharge area) and Central $\mathrm{BoB}\left(\mathrm{CB}, 80^{\circ}-92^{\circ} \mathrm{E} ; 10^{\circ}-20^{\circ} \mathrm{N}\right)$. These sub-regions are indicated as boxes in Figure $4 a$. The region NB is mainly influenced by the two largest rivers, Ganga and Brahmaputra, and eastern BoB is influenced by the Irrawaddy. Central BoB contains two rivers, Krishna and Godavari, in its western part.

Figure 6 shows seasonal variability of area-averaged FWC along with different components of freshwater input. FWC computed for three sub-regions shows similar increasing trend during southwest monsoon and decreasing trend during winter period. Maximum FWC is observed for all the three regions in October. However, maximum FWC varies significantly for each region (1.6 m for $\mathrm{CB}$, $2.4 \mathrm{~m}$ for $\mathrm{EB}$ and $4.3 \mathrm{~m}$ for $\mathrm{NB}$ ). $\mathrm{FWC}$ in $\mathrm{NB}$ and $\mathrm{CB}$ shows delayed response of two months and three months respectively, with respect to total freshwater forcing. However, this response is not smooth for EB. Total freshwater input for NB is maximum during July-August with strong contribution of $83 \%$ freshwater from river 


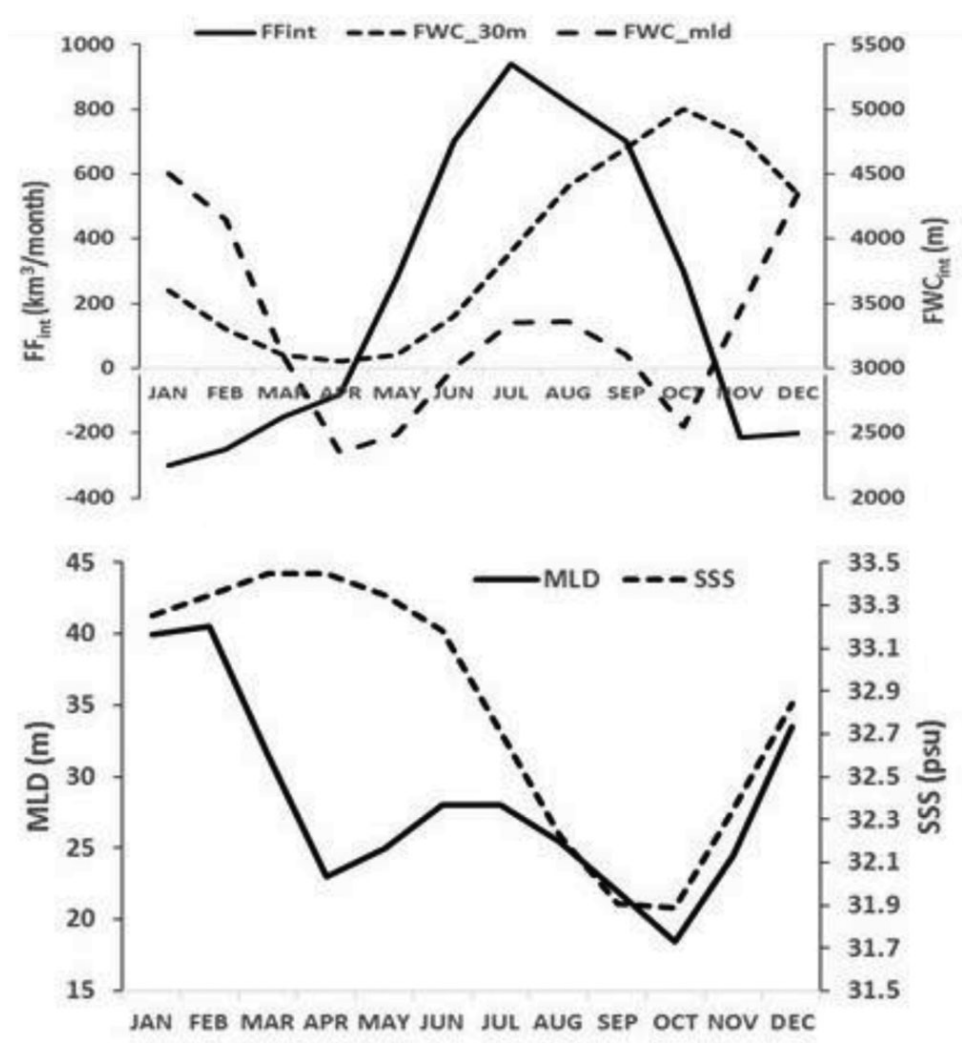

Figure 5. (Upper panel) seasonal cycle of area-integrated net freshwater input ( $\mathrm{FF}_{\text {int; }}$ left axis; $\mathrm{km}^{3} /$ month), and $\mathrm{FWC}_{\text {int }}$ (right axis; $\mathrm{km}^{3}$ ) for BoB. FWC_mld and FWC_30 m indicate FWC computed over MLD and upper $30 \mathrm{~m}$ water column respectively. (Bottom panel) seasonal cycle of MLD (left axis), and SSS (right axis) for BoB.
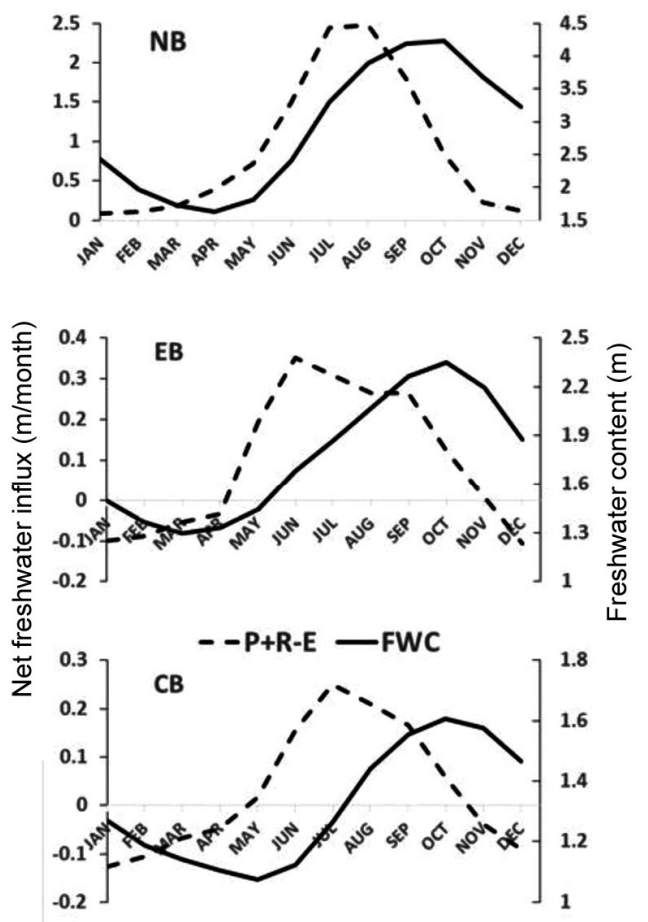
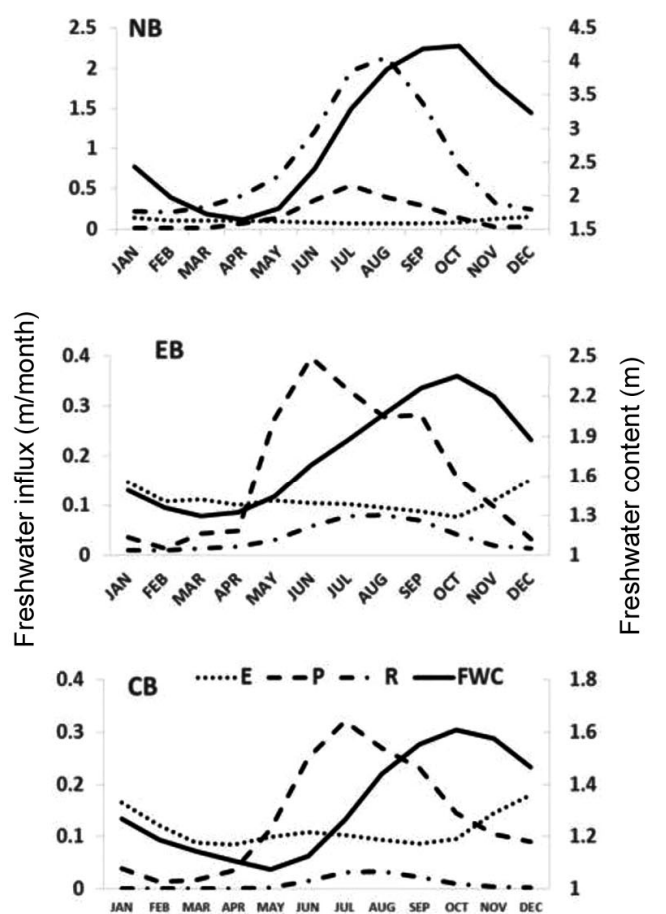

Figure 6. (Left panel) Seasonal cycle of area averaged net freshwater influx $(\mathrm{m} / \mathrm{month})$ and freshwater content (m) for different regions of BoB. (Right panel) Seasonal cycle of different components of freshwater influx such as $E, P$ and $R$ along with FWC. NB, Northernmost BoB; EB, Eastern BoB; $\mathrm{CB}$, Central BoB. 
run-off and around $20 \%$ from precipitation. To compute the contribution from river run-off, only the model points having river discharge values are taken into account. Evaporation is found to be insignificant in NB compared to other sub-regions. The salinity in NB is reduced to $22.6 \mathrm{psu}$ during August-September, one month in advance to the peak of FWC (September-October).

Salinity minimum in the NB region is in agreement with the maximum river discharge $(2.2 \mathrm{~m} / \mathrm{month})$ observed over that region during August than with maximum precipitation $(0.6 \mathrm{~m} / \mathrm{month})$ observed during July. This indicates that rapid change in salinity in NB is directly related to the large amount of river run-off from $\mathrm{G}-\mathrm{B}$ rivers. In the case of $\mathrm{CB}$, minimum SSS and maximum FWC both occur in October. In CB, change in salinity is slower and is attributed primarily to precipitation. River run-off shown in Figure 6 for $\mathrm{CB}$ is mainly from Krishna and Godavari rivers, which exhibit maximum run-off during July-August, but more confined to the western coast. Hence in $\mathrm{CB}$, net freshwater forcing mainly follows the trend of precipitation during southwest monsoon. FWC observed in this region also gets contribution from the advected freshwater from NB. It has been reported earlier that salinity at RAMA buoy located at $15^{\circ} \mathrm{N} ; 90^{\circ} \mathrm{E}$ varies coherently with rainfall (and river discharge) over catchment area with a time lag of 60 day $^{32}$. In EB, the pattern of the net freshwater input mainly follows precipitation, which is maximum during June and August-September. Negative freshwater forcing observed in CB and EB during winter is due to excess evaporation, which is not seen in the case of NB.

\section{Conclusion}

Analysed fields from the POM model run with assimilation of satellite-derived SSS are used to study the seasonality of FWC of the upper $30 \mathrm{~m}$ water column of the BoB. Comparison of model SSS with Argo-derived SSS shows an improvement of around $30 \%$ in the BoB after assimilation. Results show a clear difference between the BoB and AS as far as FWC is concerned. The BoB is mainly governed by freshwater and FWC is positive during all the seasons. For the AS, FWC is negative at some places confined mostly to the northern part. Spatial and temporal variability of FWC is caused primarily by the variability of net freshwater forcing of evaporation, precipitation and river discharge. The spatial patterns of $E, P$ and $P-E$ are studied for the BoB to understand their roles in FWC variability. Though $P-E$ is higher for the southern $\mathrm{BoB}$ from $81^{\circ}$ to $92^{\circ} \mathrm{E}$, FWC values are found to be less in that region. It is found that, in general, FWC follows a zonal pattern of increasing trend towards northern and eastern $\mathrm{BoB}$, mostly along the river discharge areas of $\mathrm{G}-\mathrm{B}$ and Irrawaddy rivers. This clearly indicates the critical role of river influx in controlling $\mathrm{FWC}$ of the $\mathrm{BoB}$. The response of FWC to total freshwater input forcing from precipitation, evaporation and river run-off has been studied for the $\mathrm{BoB}$ and the results show a delay of three months in the peak of FWC with respect to the peak of net freshwater influx. However, the response of FWC with respect to total freshwater input is found to be different among the sub-regions studied. The delay observed in the peak of FWC is two months for the northern-most BoB (mainly $\mathrm{G}-\mathrm{B}$ river discharge area) and three months for the central BoB. Compared to central and eastern BoB, salinity in the northern-most $\mathrm{BoB}$ is reduced to its lowest value rapidly, and it is observed that rapid change in salinity is directly related to the large amount of river run-off from $\mathrm{G}-\mathrm{B}$ rivers. In the central $\mathrm{BoB}$, change in salinity is slower and attributed primarily to precipitation. Since hydrological cycle of the BoB is highly influenced by precipitation and river discharge, the scientific results obtained in the present study may enhance our understanding of salinity and FWC variability in relation to total freshwater forcing. However, extensive study of FWC variability, including its transport not only in the BoB but also in the entire IO during different seasons is needed for an in-depth understanding. We are working on this aspect and the results will be reported elsewhere.

1. Sengupta, D., Bharath Raj, G. N. and Shenoi, S. S. C., Surface freshwater from Bay of Bengal runoff and Indonesian Throughflow in the tropical Indian Ocean. Geophys. Res. Lett., 2006, 33, L22609; doi:10.1029/2006GL027573.

2. Perigaud, C., McCreary, J. P. and Zhang, K. Q., Impact of interannual rainfall anomalies on Indian Ocean salinity and temperature variability. J. Geophys. Res., 2003, 108, 3319; doi:10.1029/ 2002JC001699.

3. Rao, R. R. and Sivakumar, R., Seasonal variability of sea surface salinity and salt budget of the mixed layer of the north Indian Ocean. J. Geophys. Res., 2003, 108, 3009; doi:10.1029/ 2001JC000907.

4. Sharma, R., Mankad, B., Agarwal, N., Kumar, R. and Basu, S., An assessment of two different satellite-derived precipitation products in relation to simulation of sea surface salinity in the tropical Indian Ocean, J. Geophys. Res., 2012, 117, C07001; doi:10.1029/ 2012JC008078.

5. Gadgil, S., Joseph, P. V. and Joshi, N. V., Ocean-atmosphere coupling over monsoon regions. Nature, 1984, 312, 141-143.

6. Neetu, S. et al., Influence of upper ocean stratification on tropical cyclone-induced surface cooling in the Bay of Bengal. J. Geophys. Res., 2012, 117, C12020, 3315-3329; doi:10.1029/2012JC008433/

7. Pant, V., Girishkumar, M. S., Udaya Bhaskar, T. V. S., Ravichandran, M., Papa, F. and Thangaprakash, V. P., Observed interannual variability of near-surface salinity in the Bay of Bengal, $J$. Geophys. Res., 2015, 120; doi:10.1002/2014JC010340.

8. Akhil, V. P. et al., A modeling study of the processes of surface salinity seasonal cycle in the Bay of Bengal. J. Geophys. Res., 2014, 119, 3926-3947; doi:10.1002/2013JC009632.

9. Wiffels, S. E., Schmitt, R. W., Bryden, H. R. and Stigebrandt, A., Transport of freshwater by Oceans. J. Phys. Oceanogr., 1992, 22, 155-162.

10. Behara, A. and Vinayachandran, P. N., An OGCM study of the impact of rain and river water forcing on the Bay of Bengal. J. Geophys. Res., 2016, 121, 2425-2446; doi:10.1002/ 2015JC011325. 
11. Chakraborty, A., Sharma, R., Kumar, R. and Basu, S., A SEEK filter assimilation of sea surface salinity from Aquarius in an OGCM: implication for surface dynamics and thermohaline structure. J. Geophys. Res., 2014, 119, 4777-4796; doi:10.1002/ 2014JC009984.

12. Chakraborty, A., Sharma, R., Kumar, R. and Basu, S., Joint assimilation of Aquarius-derived sea surface salinity and AVHRRderived sea surface temperature in an ocean general circulation model using SEEK filter: implication for mixed layer depth and barrier layer thickness. J. Geophys. Res., 2015, 120, 6927-6942; doi:10.1002/2015JC010934.

13. Blumberrg, A. F. and Mellor, G. L., A description of a threedimensional coastal ocean circulation model. In Three Dimensional Coastal Ocean Models (ed. Heaps, N. S.), Amer. Geophys. Union, Washington, DC, USA, 1987, pp. 1-16; doi:10.1029/ CO004P0001.

14. Mellor, G. L. and Yamada, T., Development of a turbulence closure model for geophysical fluid problems. Rev. Geophys. Space Phys., 1982, 20, 851-875.

15. Camerlengo, A. L. and O'Brien, J. J., Open boundary conditions in rotating fluids. J. Comput. Phys., 1980, 35, 12-35.

16. Santoki, M., Ratheesh, S., Sharma, R., Joshipura, K. N. and Basu, $\mathrm{S}$, Assimilation of drifter data in a circulation model of the Indian Ocean. IEEE Geosci. Remote Sensing. Lett., 2012, 9, 100-103.

17. Santoki, M., George, S., Sharma, R., Joshipura, K. N. and Basu, S., Assimilation of satellite-derived ocean surface current in an Indian Ocean circulation model. Remote Sensing Lett., 2013, 4, 475-484.

18. Ratheesh, S., Sharma, R. and Basu, S., Projection-based assimilation of satellite-derived surface data in an Indian Ocean circulation model. Mar. Geod., 2012, 35, 175-187.

19. Ratheesh. S., Sharma, R. and Basu, S., An EnOI assimilation of satellite data in an Indian Ocean circulation model. IEEE Trans. Geosci. Remote Sensing, 2014, 52, 4106-4111.

20. Oke, P. R., Brassington, G. B., Griffin, D. A. and Schiller, A., Ocean data assimilation: a case for ensemble optimal interpolation. Aust. Meteorol. Ocean J., 2010, 59, 67-76.

21. Wan, L., Bertino, L. and Zhu, J., Assimilating altimetry data into a HYCOM model of the Pacific: ensemble optimal interpolation versus ensemble Kalman filter. J. Atmos. Ocean. Technol., 2010, 27, 753-776.

22. Ratheesh. S., Sharma, R., Prasad, K. V. S. R. and Basu, S., Impact of SARAL/AltiKa-derived sea level anomaly in a data assimilative ocean prediction system for the Indian Ocean. Mar. Geod., 2015, 38, 354-364; doi:10.1080/01490419.2014.988833.

23. Levine, M., Lagerloef, G. S. E., Colomb, R., Yueh, S. and Pellerano, F., Aquarius: an instrument to monitor sea surface salinity from space. IEEE Trans. Geosci. Remote Sensing, 2007, 45, 20402050 .
24. Ratheesh, S., Sharma, R., Sikhakolli, R., Kumar, R. and Basu, S., Assessing sea surface salinity derived by Aquarius in the Indian Ocean. IEEE Geosci. Remote Sensing Lett., 2014, 11, 719-722.

25. Tang, W., Yueh, S. H., Fore, A. G. and Hayashi, A., Validation of Aquarius sea surface salinity with in situ measurements from Argo floats and moored buoys. J. Geophys. Res., 2014, 119, 6171-6189; doi:10.1002/2014JC010101.

26. Kohl, A. and Serra, N., Causes of decadal changes of the freshwater content in the Arctic Ocean. J. Climate, 2014, 27(9), 34613475 .

27. Stammer, D. et al., Volume, heat, and freshwater transports of the global ocean circulation 1993-2000, estimated from a general circulation model constrained by World Ocean Circulation Experiment (WOCE) data. J. Geophys. Res., 2003, 108(C1), 3007; doi:10.1029/2001JC001115.

28. Han, W., McCreary J. P. and Kohler, K. E., Influence of precipitation minus evaporation and Bay of Bengal rivers on dynamics, thermodynamics and mixed layer physics in the upper Indian Ocean. J. Geophys. Res., 2001, 106(C4), 6895-6916.

29. Thadathil, P., Muraleedharan, P. M., Rao, R. R., Somayajulu, Y. K., Reddy, G. V. and Revichandran, C., Observed seasonal variability of barrier layer in the Bay of Bengal. J. Geophys. Res., 2007, 112, C02009; doi:10.1029/2006JC003651.

30. Prasad, T. G., Annual and seasonal mean buoyancy fluxes for the tropical Indian Ocean. Curr. Sci., 1997, 73(8), 667-674.

31. Mahadevan, A., Spiro Jaeger, G., Freilich, M., Omand, M., Shroyer, E. L. and Sengupta, D., Freshwater in the Bay of Bengal: its fate and role in air-sea heat exchange. Oceanography, 2016, 29(2), 72-81; http://dx.doi.org/10.5670/oceanog.2016.40.

32. Rao, S. A. et al., Modulation of SST, SSS over northern Bay of Bengal on ISO time scale. J. Geophys. Res., 2011, 116, C09026; doi:10.1029/2010JC006804.

33. Chaitanya, A. V. S. et al., Observed year-to-year sea surface Salinity variability in the Bay of Bengal during the 2009-2014 period. Ocean Dyn., 2015, 65, 173-186.

34. Yu, L., A global relationship between the ocean water cycle and near-surface salinity. J. Geophys. Res., 2011, 116, C10025; doi:10.1029/2010JC006937.

ACKNOWLEDGEMENTS. We thank the Director, Space Applications Centre (SAC), Ahmedabad for motivation, and the Deputy Director, Earth, Ocean, Atmosphere, Planetary Sciences and Applications Area and the Group Director, Atmospheric and Oceanic Sciences (SAC) for encouragement. Computing facility provided by the MOSDAC team at SAC is gratefully acknowledged.

Received 28 January 2018; revised accepted 26 March 2018

doi: $10.18520 / \mathrm{cs} / \mathrm{v} 115 / \mathrm{i} 1 / 99-107$ 